\title{
Dampak Perkembangan Pariwisata Pulau Lombok terhadap Pengembangan Bandar Udara Internasional Lombok
}

\author{
The Impact of Lombok Island Tourism Development on the \\ Development of Lombok International Airport
}

\author{
Putu Agus Valguna ${ }^{1, a)}$, Dewanti ${ }^{2, b)}$ \& Latif Budi Suparma ${ }^{2, c)}$ \\ ${ }^{1)}$ Mahasiswa Magister Sistem Teknik Transportasi,Universitas Gadjah Mada, Yogyakarta \\ ${ }^{2)}$ Departemen Teknik Sipil, Universitas Gadjah Mada, Yogyakarta \\ Koresponden : a) putuagus90@mail.ugm.ac.id, ${ }^{\text {b) }}$ dewanti@ugm.ac.id \& \\ c)lbsuparma@ugm.ac.id
}

\begin{abstract}
ABSTRAK
Pulau Lombok dan Bali telah ditetapkan menjadi pintu gerbang pariwisata nasional dalam MP3EI Koridor V, sehingga membuat pariwisata yang tumbuh begitu pesat menyebabkan berkembangnya industri penerbangan yang berdampak pada bertambahnya jumlah penumpang pesawat udara. Penelitian ini bertujuan untuk menganalisis dampak pariwisata dalam hal ini jumlah wisatawan terhadap pengembangan Bandar Udara Internasional Lombok. Penelitian ini dimulai dengan mengumpulkan data primer, berupa data occupancy time kedatangan maupun keberangkatan, dan data tipe pesawat. Data sekunder terkait wisatawan dan bandar udara. Peramalan jumlah penumpang dengan menggunakan metode tren dan ekonometri kemudian untuk pengembangan bandar udara dilakukan pada fasilitas sisi udara dan darat, untuk sisi udara berupa kapasitas runway dan sisi darat berupa kapasitas terminal penumpang, metode yang digunakan untuk kapasitas runway adalah formula perhitungan ultimate capacity, sedangkan untuk kapasitas terminal menggunakan SNI-03-7046-2004. Hasil analisis menunjukkan bahwa perkembangan pariwisata di Lombok berpengaruh terhadap pengembangan bandar udara baik pada sisi udara maupun sisi darat. Pada sisi udara, kebutuhan kapasitas runway mengalami peningkatan sebesar $70 \%$ untuk tahun 2028, dengan rincian kapasitas runway yang dibutuhkan dahulu tanpa pengaruh kunjungan wisatawan adalah 6 pesawat per jam dengan pengaruh kunjungan wisatawan adalah 20 pesawat per jam. Untuk sisi darat, terminal penumpang mengalami kekurangan dalam luas sebesar 39\% antara kebutuhan di tahun 2028 dan luasan terminal penumpang saat ini, dengan rincian kekurangan luasan pada hall keberangkatan sebesar $2.142 \mathrm{~m}^{2}$, ruang tunggu keberangkatan sebanyak $735 \mathrm{~m}^{2}$, hall kedatangan sebanyak $1.255 \mathrm{~m}^{2}$, fasilitas toilet keberangkatan sebanyak $135 \mathrm{~m}^{2}$, dan fasilitas toilet kedatangan sebanyak $88 \mathrm{~m}^{2}$.
\end{abstract}

Kata Kunci : manajemen infrastruktur, pariwisata, bandar udara, fasilitas sisi darat dan udara, kapasitas runway, luasan terminal penumpang

\section{PENDAHULUAN}

Pulau Lombok dan Bali telah ditetapkan menjadi pintu gerbang pariwisata nasional dalam MP3EI (Masterplan Percepatan dan Perluasan Pembangunan Ekonomi Indonesia) koridor V. Visi kepariwisataan berkelanjutan di Lombok adalah "Lombok menjadi destinasi wisata berbasis alam dan budaya, yang berdaya saing dan berkelanjutan". Guna mewujudkan 
visi tersebut disusunlah tujuan yang didasarkan pada empat pilar utama kepariwisataan seperti yang digariskan dalam Perda NTB 7/13 Rencana Induk Pembangunan Kepariwisataan Daerah Nusa Tenggara Barat (RIPPARDA NTB) 2013 - 2028 meliputi destinasi, promosi, industri, dan kelembagaan.

Menurut Wahyuni (2019) pariwisata adalah sebuah kegiatan dimana dilakukan oleh beberapa orang atau seseorang dalam suatu perjalanan yang dapat melebihi 24 jam dari tempat tingalnya, pertumbuhan industri pariwisata berdampak pada industri penerbangan di Indonesia, hal ini dapat dilihat dari tingginya permintaan masyarakat dalam penggunaan jasa penerbangan serta jumlah pergerakan pesawat dengan tren meningkat. Banyak perusahaanperusahaan penerbangan baru yang beroperasi dengan membuka rute-rute baru dan mempertinggi frekuensi rute yang sudah ada, di pulau Lombok bahkan terjadi perpindahan lokasi bandar udara dikarenakan sudah tidak dapat berkembang lagi.

Lombok International Airport diresmikan oleh Presiden Republik Indonesia Susilo Bambang Yudhoyono pada tanggal 20 Oktober 2011. Lombok International Airport adalah bandar udara internasional yang melayani rute penerbangan domestik dan internasional yang berlokasi di kabupaten Lombok Tengah, provinsi Nusa Tenggara Barat, Indonesia. Bandar udara ini dioperasikan oleh PT Angkasa Pura I dan dibuka pertama kali pada tanggal 1 Oktober 2011 untuk menggantikan fungsi dari Bandar Udara Selaparang Mataram. Menurut Pakan (2012) peningkatan jumlah penumpang di suatu bandar udara juga berkaitan erat dengan peningkatan frekuensi penerbangan di bandar udara tesebut. Oleh sebab itu, kapasitas fasilitas sisi udara suatu bandar udara harus disampaikan secara terbuka berupa notification of apron capacity dan notification of runway capacity karena berpengaruh pada keselamatan penerbangan. Menurut Pardede (2013) jumlah wisatawan mancanegara berpengaruh positif dan signifikan terhadap permintaan penumpang, dari hasil penelitian pada tesis ini menunjukkan bahwa variabel yang paling mempengaruhi besaran jumlah penumpang jasa transportasi udara adalah jumlah wisatawan macanegara.

Perkembangan pariwisata Lombok yang begitu pesat dan akan menjadi tempat penyelenggaraan balap motor moto GP(Grand Prix) karena sedang dibangun sirkuit yang bernama sirkuit Mandalika, mendorong kebutuhan akan transportasi khususnya transportasi udara dimana bandar udara memiliki peran yang penting sebagai gerbang masuk kawasan pariwisata Lombok akan membuat peningkatan jumlah penumpang, manajemen aset infrastruktur sangat dibutuhkan untuk melakukan pengembangan bandar udara, menurut Suprayitno \& Soemitro (2018) manajemen aset insfrastruktur adalah tugas, pengetahuan, dan sains untuk mengelola infrastruktur, melalui seluruh siklus hidupnya, agar infrastruktur dapat berfungsi secara berkelanjutan, efektif, efisien, dan sesuai dengan prinsip berkelanjutan. (ekonomi, sosial, \& lingkungan).

Dari uraian di atas perlu dilakukan penelitian yang menganalisis perkembangan pariwisata pulau Lombok yang berdampak pada pengembangan bandar udara di Lombok baik dari sisi udara maupun dari sisi darat hingga tahun 2028.

\section{METODE PENELITIAN}

\section{Metode Peramalan}

\section{Metode Peramalan Trend (Time Series)}

Menurut ICAO (2006) Metode trend projection merupakan metode peramalan kuantitatif, dimana metode kuantitatif adalah metode yang didasarkan pada data kuantitatif pada masa lalu. Hasil peramalan yang dibuat sangat bergantung kepada metode peramalan yang digunakan. 
Metode trend projection merupakan metode peramalan yang menyesuaikan sebuah garis tren pada sekumpulan data masa lalu dan kemudian diproyeksikan dalam garis untuk meramalkan masa depan.

a. Linier

(sumber : ICAO(2006), sumber ini berlaku untuk rumus nomor 1-3)

$Y=a+b T$

Dimana:

$\mathrm{Y}=$ nilai terhitung dari variabel yang akan diprediksi

$\mathrm{a}=$ persilangan sumbu $\mathrm{y}$

$\mathrm{b}=$ kemiringan garis regresi

Ini menyiratkan kenaikan tahunan yang konstan dari b di tingkat lalu lintas, dan tingkat pertumbuhan yang menurun

b. Eksponensial

$$
\begin{aligned}
& Y=a(1+b)^{T} \\
& \log Y=\log a+T \log (1+b)
\end{aligned}
$$

Dimana :

$\mathrm{Y}=$ nilai terhitung dari variabel yang akan diprediksi

$\mathrm{a}=$ persilangan sumbu $\mathrm{y}$

$\mathrm{b}=$ kemiringan garis regresi

$\mathrm{T}=$ variabel bebas

Dengan b positif dan biasanya kurang dari satu, ini menyiratkan peningkatan persentase tahunan yang konstan dalam lalu lintas dengan rate 100b. Dengan mengambil logaritma, formulasi eksponensial dapat dikonversi menjadi sebuah formulasi linier.

\section{Metode Ekonometri}

Pembuatan model ekonometri merupakan salah satu sumbangan ekonometrika di samping pembuatan prediksi (peramalan atau forecasting) dan pembuatan berbagai keputusan alternatif yang bersifat kuantitatif sehingga dapat mempermudah para pengambil keputusan untuk menentukan pilihan .Dalam perhitungan peramalan menggunakan metode ekonometri ini, diberikan beberapa variabel. Beberapa variabel tersebut adalah variabel terikat (Y) serta variabel bebas (X). Berikut adalah persamaan secara linear:

$$
\mathrm{Y}=a+b X 1+c X 2
$$

Dimana :

$\mathrm{Y}=$ nilai peramalan untuk periode berikutnya

$\mathrm{a}=$ intercept

$\mathrm{b}=$ koefisien $\mathrm{X}$ Variable

$\mathrm{X}=$ Variabel bebas

(sumber Sartono dkk (2017))

\section{Formula Ultimate Capacity}

\section{Model Perhitungan Untuk Kedatangan}

Menurut Setyarini \& Ahyunadari (2017) Perubahan Runway Occupancy Time Take off (ROTT) akan berpengaruh pada nilai runway occupancy time secara keseluruhan, sedangkan perubahan nilai runway occupancy time akan mempengaruhi besarnya runway capacity. Menurut Horonjeff et al (2010) Kapasitas sistem runway untuk operasi kedatangan saja dipengaruhi oleh beberapa faktor berikut : 
a. Campuran pesawat yang biasa beroperasi berdasar kelas-kelasnya

b. Kecepatan Approach dari jenis-jenis pesawat

c. Panjang Lintasan Approach

d. Minimum Separation lalu lintas udara

e. Besarnya kesalahan waktu kedatangan di pintu masuk approach dan variasi kecepatan saat approach

f. Probabilitas pelanggaran separation minimum yang masih bisa diterima

g. Rata-rata runway occupancy times

Agar perhitungan menjadi lebih mudah, maka pesawat dikelompokkan di dalam beberapa klasifikasi kecepatan. Untuk menentukan bobot waktu pelayanan pada operasi kedatangan, diperlukan formulasi suatu matrix waktu antar pesawat yang datang.

Separasi waktu antar dua pesawat yang datang secara berurutan pada threshold runway $\left(\Delta \mathrm{T}_{\mathrm{ij}}\right)$ didapat dari pengurangan waktu saat pesawat yang di belakang $\left(\mathrm{T}_{\mathrm{j}}\right)$ melewati threshold runway dengan waktu saat pesawat di depan $\left(\mathrm{T}_{\mathrm{i}}\right)$ melewati threshold runway, yang dapat dinyatakan dalam persamaan berikut :

(sumber Horonjeff et al (2010) sumber ini berlaku untuk rumus 5 -18)

$\Delta \mathrm{T}_{i j}=T_{j}-T_{i}$

Dimana:

$\Delta \mathrm{T}_{\mathrm{ij}}=$ Separasi waktu antar dua kedatangan yang berurutan, pesawat dengan klasifikasi kecepatan i diikuti oleh pesawat dengan klas kecepatan $\mathrm{j}$

$\mathrm{T}_{\mathrm{i}}=$ Waktu saat pesawat yang di depan (i) melewati Threshold Runway

$\mathrm{T}_{\mathrm{j}}=$ Waktu saat pesawat yang di belakang (j) melewati Threshold Runway

Dalam menentukan separasi waktu antar kedatangan (interval time), sangatlah penting untuk diketahui bahwa pesawat yang di depan(leading) memiliki kecepatan lebih besar atau lebih kecil dari pesawat yang dibelakangnya (trailing). Oleh karena itu ada dua kasus yang terjadi berdasarkan kecepatan tersebut yaitu:

a. Kasus Semakin Dekat $\left(\mathrm{V}_{\mathrm{i}} \leq \mathrm{V}_{\mathrm{j}}\right)$

Jika kecepatan approach pesawat yang di depan $\left(\mathrm{V}_{\mathrm{i}}\right)$ kurang dari atau sama dengan pesawat yang dibelakang $\left(\mathrm{V}_{\mathrm{j}}\right)$ maka separasi minimum pada threshold runway merupakan pembagian antara jarak separasi minimum antar pesawat ( $\square i j$ ) dengan kecepatan pesawat yang dibelakang $\left(\mathrm{V}_{\mathrm{j}}\right)$ maka persamaannya adalah sebagai berikut :

$\Delta \mathrm{T}_{i j}=T_{j}-T_{i}=\frac{\mathrm{Q}_{i j}}{V_{j}}$

Dimana:

$\Delta \mathrm{T}_{\mathrm{ij}}=$ Separasi waktu antar dua kedatangan yang berurutan, pesawat dengan klasifikasi kecepatan i diikuti oleh pesawat dengan klas kecepatan $\mathrm{j}$

$\mathrm{T}_{\mathrm{i}}=$ Waktu saat pesawat yang di depan (i) melewati Threshold Runway

$\mathrm{T}_{\mathrm{j}}=$ Waktu saat pesawat yang di belakang (j) melewati Threshold Runway

$\square_{\mathrm{ij}}=$ Separasi minimum antar kedatangan pesawat $\mathrm{i}$ dan pesawat $\mathrm{j}$

$\mathrm{V}_{\mathrm{j}}=$ Kecepatan approach pesawat yang dibelakang

b. Kasus Semakin Jauh $\left(\mathrm{V}_{\mathrm{i}}>\mathrm{V}_{\mathrm{j}}\right)$

Jika kecepatan approach pesawat yang di depan $\left(\mathrm{V}_{\mathrm{i}}\right)$ lebih besar dari pesawat yang dibelakang $\left(\mathrm{V}_{\mathrm{j}}\right)$ maka separasi waktu minimum antar kedatangan untuk kasus pembukaan dapat dihitung dengan persamaan

$\Delta \mathrm{T}_{i j}=T_{j}-T_{i}=\frac{\square_{i j}}{V_{j}}+\gamma\left(\frac{1}{V_{j}}-\frac{1}{V_{i}}\right)$ 
Dimana :

$\Delta \mathrm{T}_{\mathrm{ij}}=$ Separasi waktu antar dua kedatangan yang berurutan, pesawat dengan klasifikasi kecepatan i diikuti oleh pesawat dengan klas kecepatan $\mathrm{j}$

$\mathrm{T}_{\mathrm{i}} \quad$ =Waktu saat pesawat yang di depan (i) melewati threshold runway

$\mathrm{T}_{\mathrm{j}}=$ Waktu saat pesawat yang di belakang (j) melewati threshold runway

$\square_{\mathrm{ij}}=$ Separasi minimum antar kedatangan

$\mathrm{V}_{\mathrm{j}}=$ Kecepatan approach pesawat yang dibelakang

$\gamma \quad=$ Panjang final approach procedure

Selanjutnya separasi waktu antar dua kedatangan ini yang didapat dari kedua persamaan diatas disusun dalam suatu metrik $\mathbf{M}_{\mathrm{ij}}$ pada Tabel 1 sebagai berikut :

Tabel 1. Susunan metrik waktu antar kedatangan ( Mij )

\begin{tabular}{c|cccccc} 
& \multicolumn{5}{|c}{ Leading $\left(\mathrm{V}_{\mathrm{i}}\right)$} \\
\hline & & $\mathrm{V}_{\mathrm{i} 1}$ & $\mathrm{~V}_{\mathrm{i} 2}$ & $\mathrm{~V}_{\mathrm{i} 3}$ & $\mathrm{~V}_{\mathrm{i} 4}$ & $\ldots$ \\
\multirow{3}{*}{$\begin{array}{c}\text { Trailing } \\
\left(\mathrm{V}_{\mathrm{j}}\right)\end{array}$} & $\mathrm{V}_{\mathrm{j} 1}$ & $\Delta \mathrm{T}_{\mathrm{i} 1 \mathrm{j} 1}$ & $\Delta \mathrm{T}_{\mathrm{i} 2 \mathrm{j} 1}$ & $\Delta \mathrm{T}_{\mathrm{i} 3 \mathrm{j} 1}$ & $\Delta \mathrm{T}_{\mathrm{i} 4 \mathrm{j} 1}$ & $\ldots$ \\
& $\mathrm{V}_{\mathrm{j} 2}$ & $\Delta \mathrm{T}_{\mathrm{i} 1 \mathrm{j} 2}$ & $\Delta \mathrm{T}_{\mathrm{i} 2 \mathrm{j} 2}$ & $\Delta \mathrm{T}_{\mathrm{i} 3 \mathrm{j} 2}$ & $\Delta \mathrm{T}_{\mathrm{i} 4 \mathrm{j} 2}$ & $\ldots$ \\
& $\mathrm{V}_{\mathrm{j} 3}$ & $\Delta \mathrm{T}_{\mathrm{i} 1 \mathrm{j} 3}$ & $\Delta \mathrm{T}_{\mathrm{i} 2 \mathrm{j} 3}$ & $\Delta \mathrm{T}_{\mathrm{i} 3 \mathrm{j} 3}$ & $\Delta \mathrm{T}_{\mathrm{i} 4 \mathrm{j} 3}$ & $\ldots$ \\
& $\mathrm{V}_{\mathrm{j} 4}$ & $\Delta \mathrm{T}_{\mathrm{i} 1 \mathrm{j} 4}$ & $\Delta \mathrm{T}_{\mathrm{i} 2 \mathrm{j} 4}$ & $\Delta \mathrm{T}_{\mathrm{i} 3 \mathrm{j} 4}$ & $\Delta \mathrm{T}_{\mathrm{i} 4 \mathrm{j} 4}$ & $\ldots$ \\
& $\ldots$ & $\ldots$ & $\ldots$ & $\ldots$ & $\ldots$ & $\ldots$ \\
\hline \multicolumn{7}{c}{ Sumber: Oka (2010) }
\end{tabular}

Nilai perkiraan waktu antar kedatangan merupakan hasil kali dari perobabilitas terjadinya urutan pesawat $i$ diikuti dengan pesawat $j$ yang disebut $p_{i j}$ dengan separasi waktu antar kedatangan pesawat $\mathrm{i}$ diikuti pesawat $\mathrm{j}$ yang telah disusun dalam matrik. Sehingga dapat dihitung dengan persamaan berikut:

$$
E\left(\Delta \mathrm{T}_{i j}\right)=\Sigma p_{i j} M_{i j}=\Sigma\left[p_{i j}\right]\left[M_{i j}\right]
$$

Dimana:

$\mathrm{E}\left(\Delta \mathrm{T}_{\mathrm{ij}}\right)=$ Nilai perkiraan waktu antar kedatangan

$\mathrm{p}_{\mathrm{ij}} \quad=$ Probabilitas kedatangan pesawat $\mathrm{i}$ diikuti pesawat $\mathrm{j}$

$\left[\mathrm{p}_{\mathrm{ij}}\right] \quad=$ Matrik $\mathrm{p}_{\mathrm{ij}}$

$\left[\mathrm{M}_{\mathrm{ij}}\right]=$ Matrik separasi waktu antar kedatangan

Jika nilai perkiraan waktu antar kedatangan yang dinyatakan dalam satuan detik diperoleh maka kapasitas runway per jam untuk operasi kedatangan bisa dihitung dari persamaan berikut:

$C_{a}=\frac{3600}{E\left(\Delta \mathrm{T}_{i j}\right)}$

Dimana :

$\mathrm{C}_{\mathrm{a}} \quad=$ Kapasitas runway untuk operasi kedatangan

$\mathrm{E}\left(\Delta \mathrm{T}_{\mathrm{ij}}\right)=$ Perkiraan waktu antar kedatangan

Model Perhitungan Untuk Keberangkatan

Jika separasi waktu minimum antar keberangkatan dinyatakan sebagai $t_{d}$, maka kapasitas runway perjam untuk operasi keberangkatan $\left(\mathrm{C}_{\mathrm{d}}\right)$ adalah:

$C_{d}=\frac{3600}{E\left(t_{d}\right)}$

Dimana :

$\mathrm{C}_{\mathrm{d}} \quad=$ Kapasitas runway untuk operasi Keberangkatan

$\mathrm{E}\left(\mathrm{t}_{\mathrm{d}}\right)=$ Perkiraan waktu antar keberangkatan 
$\mathrm{E}\left(\mathrm{t}_{\mathrm{d}}\right)$ adalah nilai perkiraan waktu antar kedatangan yang merupakan perkalian separasi waktu minimum antar keberangkatan pesawat $\mathrm{i}$ yang diikuti pesawat $\mathrm{j}$ (td) dengan probabilitas terjadinya urutan pesawat $i$ diikuti pesawat $j\left(p_{i j}\right)$, yang dinyatakan dalam persamaan ini

$$
E\left(t_{d}\right)=\Sigma\left[p_{i j}\right]\left[t_{d}\right]
$$

Dimana :

$\mathrm{E}\left(\mathrm{t}_{\mathrm{d}}\right)=$ Nilai perkiraan waktu antar keberangkatan

$\left[\mathrm{p}_{\mathrm{ij}}\right]=$ Matrik probabilitas keberangkatan

$\left[\mathrm{t}_{\mathrm{d}}\right]=$ Matrik separasi waktu minimum antar keberangkatan

\section{Model Perhitungan Campuran}

Di dalam model perhitungan campuran ada 4 hal yang perlu diketahui di dalam operasi dasar lalu lintas udara yaitu:

a. Kedatangan mempunyai prioritas utama dari pada keberangkatan

b. Hanya ada satu pesawat yang dapat menggunakan runway dalam satu waktu tertentu

c. Keberangkatan tidak dapat diijinkan jika pesawat yang dating kurang dari separasi yang ditentukan dari runway threshold

d. Separasi minimum antar pesawat yang berangkat sama dengan waktu pelayanan keberangkatan

Karena kedatangan lebih mempunyai prioritas daripada keberangkatan, pesawat yang datang diurutkan dengan minimum separasi antar kedatangan dan keberangkatan tidak dapat diijinkan kecuali ada suatu celah $G$ antar kedatangan yang dapat ditulis dalam persamaan berikut:

$$
G=T_{2}-T_{1} \geq 0
$$

Dengan nilai $\mathrm{T}_{1}$ adalah waktu saat pesawat yang datang mengosongkan runway, sedangkan $\mathrm{T}_{2}$ adalah waktu saat terakhir kalinya pesawat yang berangkat diijinkan untuk lepas landas (take off). Oleh karena itu, $\mathrm{T}_{1}$ dan $\mathrm{T}_{2}$ dihitung dengan persamaan berikut:

$$
T_{1}=T_{i}+R_{i}
$$

dan

$$
T_{2}=T_{j}-\frac{\emptyset_{d}}{V_{j}}
$$

Dengan $\mathrm{R}_{\mathrm{i}}$ adalah runway occupancy time dapat dituliskan,

$$
T_{2}-T_{1} \geq\left(T_{j}-\frac{\square_{d}}{V_{j}}\right)-\left(T_{i}-R_{i}\right) \geq 0
$$

Atau untuk mengijinkan satu keberangkatan antara dua kedatangan, maka di hitung dalam persamaan:

$$
T_{j}-T_{i} \geq R_{i}+\frac{\theta_{d}}{V_{j}}
$$

Sehingga rata-rata waktu antar kedatangan yang dibutuhkan $\mathrm{E}\left(\Delta \mathrm{T}_{\mathrm{ij}}\right)$ untuk mengijinkan $\mathrm{n}_{\mathrm{d}}$ keberangkatan antara dua kedatangan adalah:

$$
E\left(\Delta \mathrm{T}_{i j}\right) \geq E\left(R_{i}\right)+E\left(\frac{\square_{d}}{V_{j}}\right)+\left(n_{d}-1\right) E\left(t_{d}\right)
$$

Jika rata-rata waktu antar kedatangan yang dibutuhkan dalam satuan detik maka kapasitas perjam runway untuk operasi campuran adalah: 


$$
C_{m}=\frac{3600}{E\left(\Delta \mathrm{T}_{i j}\right)}\left(1+\sum n_{d} P_{n d}\right)
$$

Dimana :

$\mathrm{C}_{\mathrm{m}} \quad=$ Kapasitas runway untuk operasi campuran

$\mathrm{E}\left(\Delta \mathrm{T}_{\mathrm{ij}}\right)=$ Perkiraan waktu antar kedatangan

$\mathrm{n}_{\mathrm{d}} \quad=$ Jumlah keberangkatan yang dapat diijinkan pada setiap celah waktu antar kedatangan

$\mathrm{P}_{\mathrm{nd}} \quad=$ Probabilitas mengijinkan $\mathrm{n}_{\mathrm{d}}$ keberangkatan dalam setiap celah waktu antar kedatangan

\section{Metode Analisis Terminal Penumpang}

Menurut Pratama dkk (2015) suatu terminal penumpang bandar udara didefinisikan sebuah bangunan di bandar udara dimana penumpang berpindah antara transportasi darat dan yang membolehkan mereka menaiki dan meninggalkan pesawat. Fasilitas terminal penumpang dibedakan menjadi dua yaitu terminal pemberangkatan dan kedatangan dimana dalam perencanaan dapat dihitung dengan perhitungan standar ruang yang diatur dalam SNI-03-7046-2004.

Untuk terminal keberangkatan dan kedatangan penumpang dilakukan perhitungan pada bagian-bagian yang perlu dihitung pada Tabel 2 berikut:

Tabel 2. Rumus Perhitungan Luasan Terminal

\begin{tabular}{|c|c|c|c|}
\hline No & Bagian Terminal & Rumus & \\
\hline 1 & Hall keberangkatan & $A=0,75\{a(1+f)+b\}$ & $(19)$ \\
\hline 2 & $\begin{array}{l}\text { Ruang tunggu } \\
\text { keberangkatan }\end{array}$ & $A=c\left(\frac{u i+v k}{30}\right)+10 \%$ & $(20)$ \\
\hline 3 & Check-in Area & $A=0,25(a+b)+10 \%$ & $(21)$ \\
\hline 4 & Fasilitas Umum (Toilet) & $A=P \times 0,2 \times 1+10 \%$ & $(22)$ \\
\hline 5 & Baggage Claim Area & $A=0,9 \times c+10 \%$ & $(23)$ \\
\hline 6 & Hall Kedatangan & $A=0,375(b+c+2 \times c \times f)+10 \%$ & $(24)$ \\
\hline $\begin{array}{r}\text { Dim } \\
\text { A } \\
\mathrm{a} \\
\mathrm{b} \\
\mathrm{c} \\
\mathrm{f} \\
\mathrm{u} \\
\mathrm{v} \\
\mathrm{i} \\
\mathrm{k}\end{array}$ & $\begin{array}{l}\text { ana } \\
=\text { Kebutuhan luasan } \\
=\text { Jumlah penumpang b } \\
=\text { Jumlah penumpang tr } \\
=\text { Jumlah penumpang } \mathrm{d} \\
=\text { Jumlah pengunjung } \mathrm{p} \\
=\text { rata-rata waktu tungg } \\
=\text { rata-rata waktu tungg } \\
=\text { proporsi penumpang } \\
=\text { proporsi penumpang }\end{array}$ & $\begin{array}{l}\text { ngkat pada waktu sibuk } \\
\text { fer } \\
\text { ng pada waktu sibuk } \\
\text { genumpang } \\
\text { rlama } \\
\text { rcepat } \\
\text { nunggu terlama } \\
\text { nunggu tercepat }\end{array}$ & \\
\hline
\end{tabular}

\section{Perhitungan Aircraft Movement}

Perkiraan pergerakan pesawat dalam kelompok rute tertentu dapat diturunkan dari perkiraan penumpang, dan asumsi tentang tren masa depan dalam faktor muatan dan ukuran rata-rata pesawat. Jumlah pergerakan pesawat bisa dihitung dengan menggunakan persamaan:

Aircraft movement $=\frac{\text { passenger numbers }}{(\text { load factor }) x(\text { aircraft size })}$

Dengan :

Load Factor $=$ Penumpang yang dibawa/ jumlah seat 
Aircraft size $=$ jumlah seat yang ditawarkan / total pesawat (sumber ICAO(2006))

\section{PENGUMPULAN DATA}

Lokasi penelitian berada di Bandar Udara Internasional Lombok yang berlokasi di kabupaten Lombok Tengah, provinsi Nusa Tenggara Barat Indonesia. Data primer yang akan digunakan pada penelitian ini berupa data hasil survey occupancy time kedatangan maupun keberangkatan, dan data tipe pesawat di Perum LPPNPI (Airnav Indonesia) Cabang Lombok.

Pengambilan data sekunder dilakukan selama jam operasional di Perum LPPNPI (Airnav Indonesia) Cabang Lombok, PT Angkasa Pura I dan Dinas Pariwisata dan Kebudayaan Provinsi NTB, berupa aerodrome data Bandar Udara Internasional Lombok, kondisi cuaca (ceiling and visibility) selama survey, data pergerakan pesawat, prosedur lokal lalu lintas udara, data frekuensi pesawat berdasarkan tipe pesawat, data frekuensi urutan pesawat yang datang, data frekuensi urutan pesawat yang berangkat, data MTOW (Maximum Take Off Weight) dan klasifikasi pesawat, data jumlah pergerakan pesawat, data jumlah penumpang pesawat, data jumlah penumpang pesawat pada jam sibuk, data jumlah wisatawan nusantara dan mancanegara, data PDRB (Produk Domestik Regional Bruto), rencana induk pengembangan bandar udara, data luasan terminal penumpang eksisting

\section{ANALISIS PENELITIAN}

\section{Analisis Peramalan}

Peramalan Jumlah Kunjungan Wisatawan Yang Menggunakan Pesawat Udara

Pertumbuhan jumlah kunjungan wisatawan merupakan cerminan terhadap perkembangan pariwisata, dari data yang diperoleh dari Dinas Pariwisata dan Kebudayaan Nusa Tenggara Barat. Berdasarkan data dari Dinas Pariwisata dan Kebudayaan Nusa Tenggara Barat jumlah wisatawan mancanegara yang menggunakan bandar udara sebanyak $22,19 \%$ sedangkan jumlah wisatawan nusantara yang menggunakan bandar udara sebanyak 54,71 \% dengan asumsi komposisi ini terjadi setiap tahun dari 2010 hingga 2018 maka jumlah kunjungan wisatawan akan seperti Tabel 3

Tabel 3. Jumlah kunjungan wisatawan tahun 2010-2018 dengan pesawat udara

\begin{tabular}{ccccccc}
\hline No & Tahun & Wisman(Orang) & Wisnus(Orang) & $\begin{array}{c}\text { Wisman dengan } \\
\text { pesawat(Orang) }\end{array}$ & $\begin{array}{c}\text { Wisnus dengan } \\
\text { pesawat(Orang) }\end{array}$ & Jumlah(Orang) \\
\hline 1 & 2010 & 282.161 & 443.227 & 62.612 & 242.489 & 305.102 \\
2 & 2011 & 364.196 & 522.684 & 80.815 & 285.960 & 366.776 \\
3 & 2012 & 471.076 & 691.436 & 104.532 & 378.285 & 482.817 \\
4 & 2013 & 565.944 & 791.658 & 125.583 & 433.116 & 558.700 \\
5 & 2014 & 752.306 & 876.816 & 166.937 & 479.706 & 646.643 \\
6 & 2015 & 1.061 .292 & 1.149 .235 & 235.501 & 628.746 & 864.248 \\
7 & 2016 & 1.404 .328 & 1.690 .109 & 311.620 & 924.659 & 1.236 .280 \\
8 & 2017 & 1.430 .249 & 2.078 .654 & 317.372 & 1.137 .232 & 1.454 .604 \\
9 & 2018 & 1.204 .556 & 1.607 .823 & 267.291 & 879.640 & 1.146 .931 \\
\hline
\end{tabular}

Dengan menggunakan perbandingan metode trend dan ekonometri diperoleh hasil terbaik dengan menggunakan metode ekonometri menggunakan variabel X1 berupa jumlah penduduk NTB dan variabel X2 menggunakan PDRB berdasarkan harga konstan NTB diperoleh persamaan $\mathrm{Y}=-7.013 .247,023+1,42 \mathrm{X} 1+0,013 \mathrm{X} 2$ dengan hasil $R$ Square $=$ 0,9295 ,deviasi rata-rata terendah yaitu 81.662 orang dan nilai Sig. F sebesar 0,00131529 dimana lebih kecil dari taraf nyata sebesar 0,05. Maka diperoleh hasil peramalan seperti Tabel 4 berikut 
Tabel 4. Hasil Peramalan Jumlah Wisatawan yang Menggunakan Pesawat Terbang Sampai Tahun 2028

\begin{tabular}{ccc}
\hline No & Tahun & Wisatawan (orang) \\
\hline 1 & 2019 & 1.583 .301 \\
2 & 2020 & 1.750 .092 \\
3 & 2021 & 1.920 .349 \\
4 & 2022 & 2.094 .251 \\
5 & 2023 & 2.271 .982 \\
6 & 2024 & 2.453 .739 \\
7 & 2025 & 2.639 .728 \\
8 & 2026 & 2.830 .164 \\
9 & 2027 & 3.025 .275 \\
10 & 2028 & 3.225 .300 \\
\hline
\end{tabular}

Dari Tabel 4 dapat diperkirakan jumlah wisatawan di tahun 2028 yang menggunakan pesawat terbang berjumlah 3.225.300 orang

Peramalan Jumlah Penumpang Tahunan

Dengan menggunakan perbandingan metode trend dan ekonometri diperoleh hasil terbaik dengan menggunakan metode ekonometri menggunakan variabel X1 berupa Jumlah kunjungan wisatawan dan variabel X2 berupa jumlah pergerakan pesawat hasil $R^{2}=0,9724$ deviasi rata-rata yaitu 99.522 orang dan nilai Sig. $F$ sebesar 0,00002108247 dimana lebih kecil dari taraf nyata sebesar 0,05 dengan menggunakan persamaan yang dihasil kan oleh metode yang dipilih yaitu $\mathrm{Y}=89299,79+1,39 \mathrm{X} 1+44,216 \mathrm{X} 2$. sehingga dapat dilihat hasilnya hingga tahun 2028 pada Tabel 5 berikut

Tabel 5. Hasil Peramalan Jumlah Penumpang Tahunan Sampai Tahun 2028

\begin{tabular}{ccc}
\hline No & Tahun & Penumpang \\
\hline 1 & 2019 & 4.092 .270 \\
2 & 2020 & 4.416 .903 \\
3 & 2021 & 4.746 .358 \\
4 & 2022 & 5.080 .882 \\
5 & 2023 & 5.420 .732 \\
6 & 2024 & 5.766 .182 \\
7 & 2025 & 6.117 .517 \\
8 & 2026 & 6.475 .038 \\
9 & 2027 & 6.839 .061 \\
10 & 2028 & 7.209 .918 \\
\hline
\end{tabular}

Dari Tabel 5 bisa dilihat hasil peramalan jumlah penumpang tahunan untuk tahun 2028 diperkirakan sebanyak 7.209.918 orang.

Peramalan Jumlah Penumpang Pada Jam Sibuk Per Tahun

Dengan menggunakan perbandingan metode trend dan ekonometri diperoleh hasil terbaik dengan menggunakan metode ekonometri menggunakan variabel X1 berupa Jumlah kunjungan wisatawan dan variabel X2 berupa jumlah pergerakan pesawat hasil pada penumpang berangkat $R$ Square 0,9362 dengan rata-rata deviasi 32 orang dan nilai Sig $F$ lebih kecil dari 0,05 yaitu 0,000259, kemudian pada penumpang yang datang hasilnya adalah $R$ Square 0,8858 dengan rata-rata deviasi 52 orang dan nilai Sig $F$ yang lebih kecil dari 0,05 yaitu 0,00148. Persamaan yang terbentuk untuk keberangkatan adalah $\mathrm{Y}=747,706+$ 0,000412X1 - 0,00308X2, kemudian untuk kedatangan adalah $\mathrm{Y}=676,323+0,00046 \mathrm{X} 1-$ 0,00316 X2. sehingga dapat dilihat hasilnya hingga tahun 2028 pada Tabel 6 berikut 
Tabel 6. Hasil Peramalan Penumpang pada Jam Sibuk hingga Tahun 2028

\begin{tabular}{cccc}
\hline Tahun & $\begin{array}{c}\text { Keberangkatan } \\
\text { Total }\end{array}$ & Kedatangan Total & Total \\
\hline 2019 & 1.276 & 1277 & 2.553 \\
2020 & 1.338 & 1347 & 2.686 \\
2021 & 1.402 & 1419 & 2.821 \\
2022 & 1.468 & 1493 & 2.960 \\
2023 & 1.535 & 1568 & 3.102 \\
2024 & 1.603 & 1645 & 3.248 \\
2025 & 1.674 & 1724 & 3.397 \\
2026 & 1.746 & 1805 & 3.551 \\
2027 & 1.820 & 1888 & 3.708 \\
2028 & 1.896 & 1974 & 3.870 \\
\hline
\end{tabular}

Dari hasil peramalan pada Tabel 6 dapat dilihat bahwa jumlah penumpang di jam sibuk untuk tahun 2028 adalah 3.870 orang

Dampak Pariwisata Terhadap Jumlah Penumpang

Dengan menggunakan Persamaan yang diperoleh dari hasil peramalan baik untuk penumpang tahunan dan jam sibuk bisa dilihat jika jumlah wisatawan atau variabel wisatawan dianggap 0 (nol) maka jumlah penumpang yang menggunakan variabel wisatawan dan yang tidak menggunakan variabel wisatawan mengalami deviasi dengan ratarata deviasi sebanyak 50,04\% untuk penumpang tahunan, 47,26\% untuk penumpang berangkat pada jam sibuk, dan 52,36\% untuk penumpang yang datang pada jam sibuk.

\section{Analisis Kapasitas Runway dan Kebutuhannya di Tahun 2028}

Kapasitas Runway Untuk Operasi Kedatangan Saja

Contoh perhitungan pada Runway 13 yang memiliki FAP = 5,2 NM dan separasi lalu lintas udara antar kedatangan adalah sebagai berikut:

1. Separasi antar kedatangan ( $\square$ ) jika MTOW I >60 ton adalah 11,8 NM dari THR RWY 13

2. Separasi antar kedatangan $(\square)$ jika MTOW I $<60$ ton adalah 7,8 NM dari THR RWY 13

Selanjutnya setelah mengetahui aturan separasi antar kedatangan maka pesawat dikelompokkan berdasarkan kecepatan approach dan dicari nilai Matrix(Mij) nya, untuk itu kita memiliki dua kasus didalam perhitungan Mij sebagai berikut:

1. Kasus Semakin mendekat dengan $\mathrm{Vi}<\mathrm{Vj}$

Dengan menggunakan persamaan 6 maka kita ambil contoh $\mathrm{Vi}=86 \mathrm{Knots}$ dan $\mathrm{Vj}=$ 100 Knots maka nilai $\Delta \mathrm{T}_{\mathrm{ij}}$ diperoleh 280,8 detik

2. Kasus Semakin menjauh dengan $\mathrm{Vi} \geq \mathrm{Vj}$

Dengan menggunakan persamaan 7 maka kita ambil contoh $\mathrm{Vi}=130$ Knots dan $\mathrm{Vj}=$ 100 Knots maka nilai $\Delta \mathrm{T}_{\mathrm{ij}}$ diperoleh 468 detik

Begitu seterusnya untuk semua kecepatan pesawat yang ada sehingga akan didapatkan Matrik (Mij) pada Tabel 7 berikut

Tabel 7. Matrik Interval waktu pesawat i diikuti pesawat j (Mij)

\begin{tabular}{|c|c|c|c|c|c|c|}
\hline & & \multicolumn{5}{|c|}{ Leading (Vi) } \\
\hline & & 86 Knots & 100 Knots & 130 Knots & 140 Knots & 145 Knots \\
\hline \multirow{5}{*}{$\begin{array}{l}\text { Trailing } \\
\text { (Vj) }\end{array}$} & 86 Knots & 326,51 & 356,99 & 567,63 & 577,91 & 582,52 \\
\hline & 100 Knots & 280,8 & 280,8 & 468 & 478,29 & 482,9 \\
\hline & 130 Knots & 216 & 216 & 326,77 & 337,05 & 341,67 \\
\hline & 140 Knots & 200,57 & 200,57 & 303,43 & 303,43 & 308,04 \\
\hline & 145 Knots & 193,66 & 193,66 & 292,97 & 292,97 & 292,97 \\
\hline
\end{tabular}


Selanjutnya probabilitas terjadinya urutan pesawat yang datang berdasarkan semua kombinasi Vi dan Vj disajikan dalam matrik Pij dalam Tabel 8.

Tabel 8. Probabilitas urutan pesawat

\begin{tabular}{cllllll}
\hline & & \multicolumn{5}{c}{ Leading (Vi) } \\
& & 86 & 100 & 130 & 140 & 145 \\
& & Knots & Knots & Knots & Knots & Knots \\
\hline \multirow{3}{*}{ Trailing } & 86 Knots & 0 & 0 & 0 & 0,004 & 0 \\
(Vj) & 100 Knots & 0 & 0 & 0,0395 & 0,0237 & 0,004 \\
& 130 Knots & 0,004 & 0,0316 & 0,2134 & 0,2253 & 0,0198 \\
& 140 Knots & 0 & 0,0514 & 0,1976 & 0,1542 & 0,004 \\
& 145 Knots & 0 & 0 & 0,004 & 0,0237 & 0 \\
\hline
\end{tabular}

Kemudian nilai perkiraan interarrival time antar kedatangan dihitung menggunakan persamaan 8 dengan nilai $\mathrm{E}\left(\Delta \mathrm{T}_{\mathrm{ij}}\right)$ adalah 320,52 detik selanjutnya dengan menggunakan persamaan 9 maka diperoleh kapasitas antar kedatangan saja yaitu 11 pesawat per jam

Dari contoh perhitungan runway 13 maka dilakukan perhitungan yang sama untuk runway 31 dengan hasil disajikan pada Tabel 9

Tabel 9. Hasil Perhitungan Kapasitas Runway untuk kedatangan saja

\begin{tabular}{|c|c|c|c|c|c|}
\hline Runway & $\begin{array}{l}\text { Instrument } \\
\text { Approach }\end{array}$ & $\begin{array}{c}\text { Separasi antar } \\
\text { kedatangan }(\square)\end{array}$ & $\begin{array}{c}\text { Panjang } \\
\text { FAP } \\
(\gamma)\end{array}$ & $\mathrm{E}(\Delta \mathrm{Tij})$ & $\begin{array}{c}\text { Kapasitas } \\
\text { antar } \\
\text { arrival }\end{array}$ \\
\hline 13 & ILS & $\begin{array}{c}11,8 \text { if } \mathrm{i}>60 \text { ton; } \\
7,8 \mathrm{NM} \text { if } \mathrm{i}<60 \\
\text { ton }\end{array}$ & 5,2 NM & 320,5213 & 11 \\
\hline 31 & VOR & $11,2 \mathrm{NM}$ & 5,3 NM & 313,4123 & 11 \\
\hline
\end{tabular}

Dari Tabel 8 dapat dilihat bahwa kapasitas untuk operasi kedatangan saja pada runway 13 dan 31 sama yaitu 11 pesawat per jam

Kapasitas Runway Untuk Keberangkatan Saja

Matrik Mij waktu antar keberangkatan ( Interdeparture time) disusun berdasarkan separasi antar keberangkatan yang berlaku di Bandar Udara Internasional Lombok seperti pada Tabel 10

Tabel 10. Matrik separasi waktu antar keberangkatan

\begin{tabular}{cc|cc}
\hline \multicolumn{2}{c}{} & \multicolumn{2}{c}{ Leading/Preceeding } \\
\multicolumn{1}{c}{ Light } & Medium \\
\hline Trailing/ & Light & 60 detik & 120 detik \\
Succeeding & Medium & 60 detik & 60 detik \\
\hline
\end{tabular}

Probabilitas Pij terjadinya urutan antara pesawat yang bertipe Medium dan Light dapat dilihat pada Tabel 11

Tabel 11. Matrik Pij

\begin{tabular}{cccc}
\hline & & \multicolumn{2}{c}{ Leading/Preceeding } \\
& & Light & Medium \\
\hline Trailing/ & Light & 0 & 0,0906 \\
Succeeding & Medium & 0,0866 & 0,8228 \\
\hline
\end{tabular}

Dengan menggunakan persamaan 10 maka diperoleh nilai perkiraan waktu antar keberangkatan $\mathrm{E}(\mathrm{td})$ adalah 65,4331 detik sehingga dengan menggunakan persamaan 11 kapasitas antar keberangkatan $(\mathrm{Cd})$ adalah 55 pesawat per jam.

Kapasitas Operasi Campuran

Untuk aturan separasi antar kedatangan dan separasi antar kedatangan yang diselingi keberangkatan yang berlaku di Bandar Udara Internasional Lombok itu berbeda, maka 
interarrival time harus dihitung kembali dalam matrik Mij dan menggunakan nilai $\square$ adalah sebagai berikut:

Runway 13

1. Separasi antar kedatangan $(\square)$ jika MTOW i $>60$ ton adalah 15,8 NM dari THR RWY 13

2. Separasi antar kedatangan $(\square)$ jika MTOW i $<60$ ton adalah 12,8 NM dari THR RWY 13

3. Separasi antar kedatangan $(\square)$ jika MTOW i dan $\mathrm{j}<60$ ton adalah 7,8 NM dari THR RWY 13

Runway 31

1. Separasi antar kedatangan ( $\square$ ) jika MTOW i >60 ton adalah 16,7 NM dari THR RWY 13

2. Separasi antar kedatangan ( $\square$ ) jika MTOW i $<60$ ton adalah 13,7 NM dari THR RWY 13

3. Separasi antar kedatangan $(\square)$ jika MTOW i dan $\mathrm{j}<60$ ton adalah 8,7 NM dari THR RWY 13

Sehingga akan terbentuk matrik Mij untuk runway 13 dalam Tabel 12

Tabel 12. Matrik Interval waktu pesawat i diikuti pesawat $\mathrm{j}$ operasi mix

\begin{tabular}{|c|c|c|c|c|c|c|}
\hline & & \multicolumn{5}{|c|}{ Leading (Vi) } \\
\hline & & 86 & 100 & 130 & 140 & 145 \\
\hline & & Knots & Knots & Knots & Knots & Knots \\
\hline \multirow{5}{*}{ Trailing (Vj) } & $\begin{array}{l}86 \\
\text { Knots }\end{array}$ & 326,51 & 356,99 & 735,07 & 745,36 & 749,97 \\
\hline & $\begin{array}{l}100 \\
\text { Knots }\end{array}$ & 280,8 & 280,8 & 612 & 622,29 & 626,9 \\
\hline & $\begin{array}{l}130 \\
\text { Knots }\end{array}$ & 354,46 & 354,46 & 437,54 & 447,82 & 452,44 \\
\hline & $\begin{array}{l}140 \\
\text { Knots }\end{array}$ & 329,14 & 329,14 & 406,29 & 406,29 & 410,9 \\
\hline & $\begin{array}{l}145 \\
\text { Knots }\end{array}$ & 317,79 & 317,79 & 392,28 & 392,28 & 392,28 \\
\hline
\end{tabular}

Selanjutnya dengan hasil matrik Mij pada Tabel 12, dengan menggunakan Persamaan 8 maka diperoleh nilai waktu Interarrival untuk runway 13 dengan aturan separasi campuran $\mathrm{E}(\Delta \mathrm{Tij})$ adalah 433 detik sehingga dengan menggunakan persamaan 10 diperoleh kapasitas antar kedatangan 8 pesawat per jam.

Selanjutnya dihitung waktu antar kedatangan dengan diselingi oleh suatu keberangkatan dengan separasi antar keberangkatan yang diikuti kedatangan ( $\square$ d) adalah 5 $\mathrm{NM}$, tahapan selanjutnya melakukan pengelompokkan pesawat berdasarkan tipenya dnegan occupancy time dan probabilitasnya, disajikan pada Tabel 13

Tabel 13. Probabilitas Frekuensi Pesawat berdasarkan Occupancy Time

\begin{tabular}{lcc}
\hline \multicolumn{1}{c}{ Tipe Pesawat } & Occupancy Time & Probabilitas \\
\hline Airbus 320 Family & 185 & 0,232209738 \\
\hline Boeing 737 All Series & 190 & 0,417602996 \\
ATR 72 Series & 160 & 0,239700375 \\
Cessna 208 Caravan & 80 & 0,078651685 \\
Cessna 172 Skyhawk & 40 & 0,005617978 \\
Bombardier CRJ-1000 & 70 & 0,026217228 \\
\hline
\end{tabular}

Dari Tabel 12 dilakukan perhitungan untuk nilai penjumlahan occupancy time $\mathrm{E}(\mathrm{Ri})$ dengan hasil 169,007 detik, kemudian tiap pesawat dikelompokkan berdasarkan kecepatan approach dan dihitung probabilitasnya berdasarkan frekuensinya pada Tabel 14 . 
Tabel 2. Probabilitas Frekuensi Pesawat berdasarkan Kecepatan Approach

\begin{tabular}{lcr}
\hline \multicolumn{1}{c}{ Tipe Pesawat } & $\begin{array}{c}\text { Kecepatan } \\
\text { Approach }\end{array}$ & Probabilitas \\
\hline Airbus 320 Family & 130 & 0,232209738 \\
Boeing 737 All Series & 140 & 0,417602996 \\
ATR 72 Series & 130 & 0,239700375 \\
Cessna 208 Caravan & 100 & 0,078651685 \\
Cessna 172 Skyhawk & 86 & 0,005617978 \\
Bombardier CRJ-1000 & 145 & 0,026217228 \\
\hline
\end{tabular}

Dari tabel 14 dapat dihitung nilai $E\left(\frac{\square_{d}}{V_{j}}\right)$ dengan hasil 137,621 detik, sehingga waktu antar kedatangan untuk diselingi keberangkatan adalah sebagai berikut :

$$
\begin{aligned}
& E\left(\Delta \mathrm{T}_{i j}\right) \geq 169,007+137,621+65,4331\left(n_{d}-1\right) \\
& E\left(\Delta \mathrm{T}_{i j}\right) \geq 306,628+65,4331\left(n_{d}-1\right)
\end{aligned}
$$

Dari hasil ini maka waktu yang dibutuhkan untuk 2 kedatangan yang diselingi 1 keberangkatan adalah 306,628 detik sedangkan untuk deselingi 2 keberangkatan diperlukan 372,061 detik tetapi karena aturan separasi yang digunakan adalah untuk dua kedatangan yang diselingi satu keberangkatan maka semua kombinasi urutan kedatangan pesawat hanya bisa diselingi satu keberangkatan sehingga nilai $\mathrm{n}_{\mathrm{d}}=1$ dan probabilitas kedatangan yang diselingi keberangkatan $\mathrm{P}_{\mathrm{nd}}=1$, jadi kapasitas runway dalam operasi mix untuk runway 13 menggunakan Persamaan 18 adalah 16 pesawat per jam, dengan cara yang sama digunakan untuk menghitung runway 31 disajikan dalam Tabel 15

\begin{tabular}{|c|c|c|c|c|c|c|}
\hline Runway & $\begin{array}{c}\text { Instrument } \\
\text { Approach }\end{array}$ & $\begin{array}{c}\text { Separasi antar } \\
\text { kedatangan }(\square)\end{array}$ & $\begin{array}{c}\text { Panjang FAP } \\
(\gamma)\end{array}$ & $\mathrm{E}(\Delta \mathrm{Tij})$ & $\begin{array}{c}\text { Kapasitas } \\
\text { antar arrival }\end{array}$ & $\begin{array}{l}\text { Kapasitas } \\
\text { Campuran }\end{array}$ \\
\hline 13 & ILS & $\begin{array}{c}15,8 N M \text { if } i>60 \\
\text { ton; } 12,8 \text { NM if } i< \\
60 \text { ton; } 7,8 N M \text { if } i \\
\text { dan } j<60\end{array}$ & $5,2 \mathrm{NM}$ & 433 & 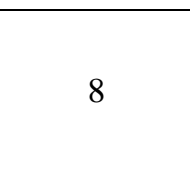 & 16 \\
\hline 31 & VOR & $\begin{array}{c}16,7 N M \text { if } i>60 \\
\text { ton; } 13,7 N M \text { if } i< \\
60 \text { ton; } 8,7 N M \text { if } i \\
\text { dan } j<60\end{array}$ & 5,3 NM & 453 & 7 & 15 \\
\hline
\end{tabular}

Tabel 15. Hasil Perhitungan Kapasitas Kedua Runway

Untuk perhitungan delay, cuaca dan faktor lain maka kapasitas praktis suatu runway adalah $80 \%$ sampai $90 \%$ dari kapasitas jenuh, maka kapasitas praktis runway 13 adalah $80 \%$ x $16=12,8$ dibulatkan 12 pesawat per jam, sedangkan untuk runway 31 adalah $80 \%$ x $15=$ 12 pesawat per jam, jadi kapasitas praktis untuk runway 13 dan 31 adalah sama yaitu 12 pesawat per jam.

Kebutuhan Kapasitas Runway Hingga Tahun 2028

Dari data yang diperoleh di lapangan jumlah pesawat di peak hour tahun 2019 adalah 13 pesawat per jam per hari, hal ini sudah menunjukkan bahwa terjadi kejenuhan kapasitas runway pada saat jam sibuk sesuai dengan hasil hitung kapasitas praktis yaitu sebanyak 12 pesawat per jam per hari, untuk mendapatkan hasil kebutuhan di tahun 2028 maka harus ditentukan nilai load factor dari persamaan 25 untuk tahun 2019 dengan pesawat yang diperhitungkan adalah tipe Boeing 737 all series dan tipe Airbus 320 dengan jumlah kursi yang tersedia rata-rata 230 didapatkan load factor pesawat $85 \%$.

Dengan prilaku transportasi udara yang memntingkan efisiensi, artinya apabila penumpang bertambah banyak maka bukan frekuensi penerbangannya yang ditambah tapi type pesawatnya yang di ganti maka diasumsikan nilai load factor dianggap sama untuk digunakan pada tahun 2028 maka didapatkan kebutuhan kapasitas untuk tahun 2028 adalah 20 pesawat per jam. 
Dengan cara yang sama dan load factor yang sama maka dilakukan perhitungan dengan menggunakan jumlah penumpang berangkat dan datang pada jam sibuk tanpa adanya penumpang wisatawan dengan jumlah 1.052 orang sehingga kebutuhan kapasitas untuk tahun 2028 tanpa adanya wisatawan adalah 6 pesawat perjam

\section{Analisis Kebutuhan Landside Berupa Terminal Penumpang Di Tahun 2028}

Analisis kebutuhan dilakukan dengan menggunakan standar minimal yang berlaku di Indonesia, kebutuhan luasan terminal penumpang yang dihitung adalah:

1. Hall Keberangkatan

2. Check In Area

3. Ruang Tunggu Keberangkatan

4. Bagage Claim Area

5. Hall Kedatangan

6. Fasilitas Umum(Toilet Keb)

7. Fasilitas Umum(Toilet Ked)

Dengan menggunakan Persamaan 19 - 24 maka diperoleh hasil perhitungan untuk tahun 2028 pada Tabel 16

Tabel 3. Kebutuhan Luasan Terminal Tahun 2028

\begin{tabular}{|c|c|c|c|c|}
\hline No & Fasilitas Sisi Darat & $\begin{array}{c}\begin{array}{c}\text { Existing } \\
\left(\mathrm{m}^{2}\right)\end{array} \\
\end{array}$ & $\begin{array}{c}\text { Kebutuhan } \\
\text { minimal }\left(\mathrm{m}^{2}\right)\end{array}$ & Kekurangan $\left(\mathrm{m}^{2}\right)$ \\
\hline 1 & Hall Keberangkatan & 2756 & 5.331 & 2.575 \\
\hline 2 & Check In Area & 2290 & 734 & \\
\hline 3 & $\begin{array}{l}\text { Ruang Tunggu } \\
\text { Keberangkatan }\end{array}$ & 1247 & 2.169 & 923 \\
\hline 4 & Bagage Claim Area & 2721 & 1.954 & \\
\hline 5 & Hall Kedatangan & 2756 & 4.390 & 1.634 \\
\hline 6 & $\begin{array}{l}\text { Fasilitas Umum(Toilet } \\
\text { Keb) }\end{array}$ & 248 & 417 & 169 \\
\hline 7 & $\begin{array}{l}\text { Fasilitas Umum(Toilet } \\
\text { Ked) }\end{array}$ & 309 & 434 & 125 \\
\hline
\end{tabular}

Dari Tabel 16 dapat dilihat perhitungan kebutuhan luasan terminal yang dipengaruhi oleh wisatawan, dengan menggunakan metode yang sama maka akan dihitung kebutuhan luasan terminal dengan menganggap jumlah wisatawan yang menggunakan pesawat udara dianggap 0 (nol) sehingga akan didapatkan hasil perbadingannya pada Tabel 17 berikut

Tabel 4. Perbandingan Kebutuhan Luasan Terminal Dengan dan Tanpa Adanya Wisatawan pada Tahun 2028

\begin{tabular}{|c|c|c|c|c|}
\hline No & Fasilitas Sisi Darat & $\begin{array}{c}\text { Existing } \\
\left(\mathrm{m}^{2}\right)\end{array}$ & $\begin{array}{c}\text { Kebutuhan minimal } \\
\text { dengan adanya } \\
\text { wisatawan }\left(\mathrm{m}^{2}\right)\end{array}$ & $\begin{array}{c}\text { Kebutuhan minimal } \\
\text { tanpa adanya } \\
\text { wisatawan }\left(\mathrm{m}^{2}\right)\end{array}$ \\
\hline 1 & Hall Keberangkatan & 2756 & 5.331 & 1570 \\
\hline 2 & Check In Area & 2290 & 734 & 213 \\
\hline 3 & $\begin{array}{ll}\text { Ruang } & \text { Tunggu } \\
\text { Keberangkatan } & \end{array}$ & 1247 & 2.169 & 535 \\
\hline 4 & Bagage Claim Area & 2721 & 1.954 & 483 \\
\hline 5 & Hall Kedatangan & 2756 & 4.390 & 1093 \\
\hline 6 & $\begin{array}{l}\text { Fasilitas Umum(Toilet } \\
\text { Keb) }\end{array}$ & 248 & 417 & 124 \\
\hline 7 & $\begin{array}{l}\text { Fasilitas Umum(Toilet } \\
\text { Ked) }\end{array}$ & 309 & 434 & 107 \\
\hline
\end{tabular}


Dari Tabel 17 dapat dilihat bahwa pengaruh wisatawan dalam kebutuhan minimal luasan terminal cukup besar dengan perbedaan rata-rata 39\% antara kebutuhan dengan adanya wisatawan dan tanpa adanya wisatawan di tahun 2028.

\section{KESIMPULAN DAN SARAN}

\section{Kesimpulan}

Dari hasil penelitian dapat diketahui bahwa peramalan jumlah wisatawan yang menggunakan pesawat udara hingga tahun 2028 adalah 3.225 .300 orang, jumlah penumpang pesawat udara pertahun hingga tahun 2028 adalah 7.209.918 orang. Jumlah penumpang jam sibuk di tahun 2028 untuk penumpang berangkat adalah 1.896 orang dan penumpang datang adalah 1.974 orang. Dampak yang diberikan oleh jumlah wisatawan pengguna pesawat udara adalah 50,04\% untuk penumpang tahunan, $47,26 \%$ untuk penumpang berangkat pada jam sibuk, dan 52,36\% untuk penumpang yang datang pada jam sibuk. Kapasitas runway praktis yang tersedia untuk tahun 2019 adalah 12 pesawat dengan kebutuhan di tahun 2028 adalah 20 pesawat dengan adanya dampak pariwisata sedangkan jika tanpa adanya pariwisata kebutuhan kapasitas runway di tahun 2028 hanya 6 pesawat. Untuk kebutuhan luasan terminal diperoleh hasil kekurangan luasan pada hall keberangkatan sebanyak $2.142 \mathrm{~m}^{2}$, ruang tunggu keberangkatan sebanyak $735 \mathrm{~m}^{2}$, hall kedatangan sebanyak $1.255 \mathrm{~m}^{2}$, fasilitas toilet keberangkatan sebanyak $135 \mathrm{~m}^{2}$, dan fasilitas toilet kedatangan sebanyak $88 \mathrm{~m}^{2}$. Pengaruh perkembangan kunjungan wisatawan untuk pengembangan bandar udara baik sisi udara maupun sisi darat sangat besar dengan perbedaan mencapai $70 \%$ dalam kebutuhan kapasitas runway untuk sisi udara dan rata-rata $39 \%$ dalam kekurangan luasan terminal penumpang dari kondisi sekarang untuk sisi darat.

\section{Saran}

Perlu diadakan kajian lebih lanjut terkait perkembangan pariwisata untuk menjalankan Perda No. 7 tahun 2013 terkait dengan jumlah akomodasi khususnya di pulau Lombok. Perlu adanya pengadaan fasilitas navigasi penerbangan berupa surveillance sehingga aturan separasi bisa dikurangi untuk menambah jumlah kapasitas runway. Perlu melakukan restrukturisasi ruang udara upper Lombok agar di handle oleh Bali director sehingga Lombok menjadi TWR murni bukan lagi combined unit yang menggunakan non radar service. Melakukan kajian kembali terkait prosedur separasi pesawat antar kedatangan maupun antar kedatangan yang diselingi satu pesawat berangkat. Perlu melakukan pengembangan airside berupa penambahan rapid exit taxiway sebagai jalan keluar pesawat sehingga occupancy time menjadi lebih singkat. Perlu penyamaan kekuatan perkerasan dari fasilitas landside terutama pada taxiway dan apron sehingga bisa menambah jumlah kapasitas runway. Mengembangkan terminal penumpang sesuai dengan analisa kebutuhan minimal terminal penumpang yang sudah dihitung pada penelitian ini

\section{DAFTAR PUSTAKA}

Horonjeff, R., McKelvey, F., Sproule, W., \& Young, S. (2010). Planning and Design Of Airport.Fifth Edition. Mc Graw Hill. New York

ICAO (2006). Manual on Air Traffic Forcasting. Doc 8991. International Civil Aviation Organization.

Oka, I. G. (2010). "Analisis Perhitungan Kapasitas Runway Bandar Udara Soekarno Hatta". Jurnal Ilmiah Aviasi Langit Biru, Vol 3 No 8.

Pakan, W. (2012). "Capacity Improvement Necessities Of Airside Facility In Airports Under The Management Of PT Angkasa Pura I". Warta Ardhia Jurnal Perhubungan Udara, Vol.38 No.3. 
Pardede, R. P. (2013). "Analisis Faktor - Faktor Yang Mempengaruhi Permintaan Penumpang Maskapai Penerbangan Garuda Indonesia Airlines".Tesis.Program Pascasarjana. Universitas Negeri Medan.

Perda NTB 7/13. (2013). Peraturan Daerah Provinsi Nusa Tenggara Barat Nomor 7 Tahun 2013 Rencana Induk Pembangunan Kepariwisataan Daerah tahun 2013-2028. Indonesia.

Pratama, P. Y., Purbanto, I. R., \& Suweda, I. (2015). "Analisis Kebutuhan Fasilitas Terminal Penumpang Domestik". Jurnal Ilmiah Teknik Sipil, Vol. 19 No. 1.

Setyarini, C., \& Ahyudanari, E. (2017). "Analisis Pengaruh Pergeseran Runway Holding Position Terhadap Runway Occupancy Time runway capacity (studi kasus Bandar Udara Internasional Juanda)". Warta Ardhia Jurnal Perhubungan Udara, Vol 43 No. 2.

Sartono, W., Dewanti, \& Rahman, T. (2017). Bandar Udara. Gadjah Mada University Press. Yogyakarta.

SNI 03-7046-2004. (2004). SNI 03-7046-2004 Terminal Penumpang Bandar Udara. Indonesia.

Suprayitno, H., \& Soemitro, R. A. (2018). "Preliminary Reflexion on Basic Principle of Infrastructure Asset Management". Jurnal Manajemen Aset Infrastruktur \& Fasilitas, Vol. 2, No. 1.

Wahyuni, S. (2019). "Analisis Pariwisata Budaya dalam Pengembangan Aset Lokal Perayaan Upacara Adat Dahau di Kabupaten Kutai Barat Provinsi Kalimantan Timur". Jurnal Manajemen Aset Infrastruktur \& Fasilitas, Vol. 3, No. 1. 